\title{
Sleep in child and adolescent psychiatry: overlooked and underappreciated
}

\author{
Leila Tarokh • Christoph Hamann • \\ Benno G. Schimmelmann
}

Published online: 13 May 2014

(C) Springer-Verlag Berlin Heidelberg 2014

\begin{abstract}
"Disease exists, if either sleep or watchfulness be excessive" Hippocrates, Aphorism LXXI.
\end{abstract}

The above quote of Hippocrates dates back more than 2,000 years and demonstrates that a connection between sleep and health has long been recognized. Psychiatric disorders are no exception, with abnormal sleep patterns manifesting in nearly all mental disorders. The importance of sleep in psychiatric disorders can be seen in the incorporation of sleep in the diagnostic criteria for many disorders (classified according to the DSM 5 [1] and ICD-10) and applicable not only to adults, but also children and adolescents. More recently, the NIMH based research domain criteria (RDoC) initiative, which hopes to develop “... new ways of classifying mental disorders based on dimensions of observable behavior and neurobiological measures", has named sleep (within arousal/regulatory systems) as one of five research domains, further highlighting the importance of sleep in future research and intervention in psychiatry [2].

Altered sleep patterns in psychiatric illness take varying forms, but are outwardly apparent to patients and clinicians under the umbrella term "disrupted sleep", which includes difficulty falling asleep, staying asleep, waking too early, ill-timed sleep, interrupted or non-restorative sleep and daytime sleepiness. Subjective complaints of troubled sleep by patients have been confirmed using objective and physiological measures of sleep. In a meta-analysis of sleep in adults with psychiatric disorders, Benca and colleagues [3] found that individuals in most psychiatric diagnostic

L. Tarokh $(\bowtie) \cdot$ C. Hamann · B. G. Schimmelmann University Hospital of Child and Adolescent Psychiatry and Psychotherapy, University of Bern, Bolligenstr. 111, Haus A, 3000 Bern 60, Switzerland e-mail: leila.tarokh@kjp.unibe.ch categories, ranging from mood disorders to schizophrenia, showed signs of disrupted sleep. For example, over $80 \%$ of depressed patients complain of difficulties falling or staying asleep. Furthermore, the magnitude of sleep problems is often linked to disease severity and, importantly, quality of life [4], making sleep an important therapeutic target for improving overall well-being.

Despite the prevalence of sleep disruption in psychiatric illness, the precise mechanism(s) of the interaction remains unclear. Recent evidence suggests that this comorbidity may in part be due to common pathways and mechanisms. For example, several genes, intimately involved in the generation and regulation of circadian rhythms and sleep, have been linked to mental illness and vice versa [5-8]. Furthermore, psychiatric disorders are often associated with abnormal brain functioning-from neurotransmitter signaling to cortical network connectivity. As sleep is a complex state, dependent on efficacious brain functioning on multiple levels (e.g., neurotransmitters to networks), the fact that many psychiatric disorders are accompanied by a sleep phenotype is to be expected [9]. Thus, the aberrations in cortical functioning underlying psychiatric illness may also manifest as disrupted or irregular sleep.

Much of the work regarding sleep in psychiatric populations has focused on adults; however, psychiatric disorders in childhood and adolescence are just as, if not more, important. For one, many psychiatric disorders have their peak onset during adolescence [10]. Some have speculated that this may be due to the neurobiological changes that occur during adolescence. The most striking among these is a significant cortical restructuring during which cortical grey matter volume plummets concurrent with an increase in white matter volume [11]. Furthermore, symptom persistence in mental disorders is higher during adolescence than during adulthood, and early onset of psychiatric illness seems to be 
associated with marked and often persistent functional impairment as well as increased mortality $[12,13]$.

Against the background of cortical remodeling and changes in behavioral, social, emotional and cognitive function that occur during adolescence, sleep physiology and behavior also undergo significant transformation. With regard to sleep physiology, one of the most readily observable changes is a decline in low-frequency, high-amplitude waves referred to as slow wave or deep sleep $[14,15]$. The decline in this measure has been hypothesized to reflect the decline in cortical grey matter volume observed in this developmental period [16]. Notably, the topographic distribution of this measure over the brain has been shown to be altered in a number of psychiatric disorders in childhood and adolescence and may be a promising measure for detection and early intervention [17].

Concurrent to the changes in sleep physiology is a behavioral truncation of sleep duration across adolescence driven by later and later bedtimes, while rise time stays the same or is even earlier due to school schedules [18]. The later bedtimes are driven in part by changes in the biological systems that regulate sleep and manifest as a preference for later bedtimes in more mature adolescents (reviewed in [19]). Working together with the biological changes, are the evolving social environment and roles prescribed for teens, which further encourage later bedtimes. Such environmental changes include increased independence, socializing with peers at night, extracurricular activities (e.g., sports, part time jobs, etc.), increased exposure to media (e.g., computers, tablets, smart phones, television) and consumption of caffeinated drinks. Despite the later bedtimes and shorter sleep duration with each passing year, studies suggest that the amount of sleep that adolescents "need" does not change and optimal number of hours is between 8.5 and $9.5 \mathrm{~h}$ [20]. However, a poll of 1,600 American teens showed that sleep duration declines from $8.4 \mathrm{~h}$ at around age 12 years to $6.9 \mathrm{~h}$ at age 18 years [18]. This trend of declining sleep has been found in most other countries studied, including many European countries (reviewed in [21]).

With regard to mental health, this declining sleep duration during adolescence is of concern. Numerous studies have shown the negative impact of an acute sleep restriction on mood [22], anxiety [23], attention [24], cognitive performance [24] and decision-making in otherwise healthy individuals. The long-term effects of such a volitional truncation in sleep duration remain unknown, but short sleep duration has been prospectively linked to the onset and persistence of psychological distress in young adults [25] and behavioral problems in children [26]. Furthermore, short sleep has been shown to predict excessive weight gain and obesity [27, 28].
In addition to the behaviorally induced decline in sleep duration, problems falling and staying asleep also emerge during adolescence. For example, the National Sleep Foundation poll found that $26 \%$ of adolescents between the ages of 12 and 18 had a delayed sleep onset (30 min of more) and $31 \%$ reported having difficulty staying asleep at night on one occasion or more in the last 2 weeks [18]. This disrupted sleep is of concern as it may be a marker of vulnerability for the development of psychiatric disorders. Indeed, numerous studies conducted in various countries using different methodologies have found an association between disrupted sleep and suicidal ideation, suicide attempts and completed suicide [29-33]. In fact, disturbances in sleep duration, timing and quality are commonly reported to precede the onset of many psychiatric disorders and may be a useful predictor of future psychiatric problems particularly in youth [34]. To summarize, based on the current literature, it appears that disrupted sleep may be a marker of a pre-existing vulnerability, while the behaviorally induced sleep restriction that many adolescents put themselves through may contribute to the development or exacerbation of mental disorders in adolescents. Thus ensuring adequate and restorative sleep may be a preventive measure to increase resilience in this age.

Fortunately sleep behavior is modifiable and several therapeutic approaches exist. For one, patients will benefit from education regarding proper "sleep hygiene" which entails stabilizing sleep/wake rhythms by going to bed and waking up at the same time each day and avoiding naps. Furthermore, nighttime activities play an important role in sleep hygiene and quality. For example, teens should avoid activities that are arousing or stressful, such as checking social media right before bed. This is indeed a problem as $55 \%$ of teens between the ages of 15-18-year-olds surf the web and $56 \%$ send or receive text messages almost every night of the week within an hour of going to bed [35]. In addition to being arousing, use of electronic media at night exposes teens to bright light, which sends an arousing cue to the brain, interfering with sleep onset and maintenance. Thus teens can benefit from taking cell phones out of the bedroom at night and restricting computer and television use in the hour before bed.

In addition to good sleep hygiene, an established literature points to the efficacy of cognitive behaviour therapy for insomnia (CBT-I) in adults [36-38]. CBT-I consists of several behavioral techniques and setting achievable expectations about sleep (e.g., it is ok not to sleep for $8 \mathrm{~h}$ a night) to normalize sleep-wake behavior. Despite the fact that most youths and their parents favor psychotherapy over pharmacotherapy [39], and that CBT appears to be superior to sleep medication in the long term [37, 40], 
outcome literature on youth insomnia treatment is limited and desperately needed.

Given that improving sleep is possible, clinicians should initially assess whether sleep is a problem in their patients and consider treatment of sleep problems as an adjunct to therapy to improve outcomes, particularly in depression and bipolar disorder [41]. Assessment of sleep can take a variety forms. The most basic diagnostic method is the sleep $\log$ in which patients record what time they went to bed, woke up, and how often they woke in the night. The sleep log provides a more specific and accurate estimate of the reported sleep disturbance than global reports. Actigraphy, an indirect measure of sleep-wake by means of motion monitoring, can also be a helpful tool in assessment of patients [42]. Modern devices are sleek bracelets that can be integrated easily in everyday life and patients can synchronize their data with smart phone applications that give feedback in real time. These methods can be used to measure not only the extent of sleep difficulties, but also assess the impact of medication and therapy on sleep patterns. They can also help patients understand how their sleep impacts their daytime mood and wellbeing. Finally, successful treatment of youth insomnia may improve outcomes in other domains as well including improved educational attainment, reduced school dropout rates and improved classroom performance [43]. Therefore, the treatment of sleep disturbances might also improve public health in general.

Despite the significant progress that has been made in understanding the role of sleep in psychiatric disorders, many questions remain unanswered. For example, more research is needed to understand how the chronic behavioral shortening of sleep in adolescence impacts long-term mental health, particularly in teens with a pre-existing vulnerability. Such paradigms require longitudinal monitoring of sleep using objective measures, such as actigraphy, rather than questionnaires at a single time point. Furthermore, sleep is a unique time to examine brain activity unperturbed by factors which impact waking measures (e.g., attention and motivation). Thus the search for biological markers that precede the onset of a psychological disorder may be more fruitful in sleep than in waking. Finally, randomized controlled trials should examine the efficacy of sleep related interventions in improving mental health outcomes in teens with psychiatric disorders.

Given the predominance of sleep problems in children and adolescents with psychiatric disorders, clinicians and parents should work together to stabilize sleep/wake patterns to improve outcomes. Here we have highlighted the role of sleep in psychiatric disorders, some of the factors that contribute to disrupted sleep in adolescence, and methods that can be used to positively impact sleep.
Adolescence is a period of vulnerability and opportunity. By intervening and protecting sleep in this critical developmental period we may be able to impact a host of domains, including mental health, cognition, a healthy weight and promote an overall sense of well-being. After all, humans spend a significant portion of their time sleeping, and we are only beginning to uncover the benefits of sleep for the mind and body.

\section{References}

1. Association AP (2013) Diagnostic and statistical manual of mental disorders, 5th edn. American Psychiatric Publishing, Arlington

2. Insel TR (2014) The NIMH research domain criteria (RDoC) project: precision medicine for psychiatry. Am J Psychiatry 171(4):395-397. doi:10.1176/appi.ajp.2014.14020138

3. Benca RM, Obermeyer WH, Thisted RA, Gillin JC (1992) Sleep and psychiatric disorders. a meta-analysis. Arch Gen Psychiatry 49(8):651-668 (discussion 669-670)

4. Cohrs S (2008) Sleep disturbances in patients with schizophrenia: impact and effect of antipsychotics. CNS Drugs 22(11):939-962

5. Wulff K, Porcheret K, Cussans E, Foster RG (2009) Sleep and circadian rhythm disturbances: multiple genes and multiple phenotypes. Curr Opin Genet Dev 19(3):237-246. doi:10.1016/j. gde.2009.03.007

6. Jagannath A, Peirson SN, Foster RG (2013) Sleep and circadian rhythm disruption in neuropsychiatric illness. Curr Opin Neurobiol 23(5):888-894. doi:10.1016/j.conb.2013.03.008

7. Nievergelt CM, Kripke DF, Barrett TB, Burg E, Remick RA, Sadovnick AD, McElroy SL, Keck PE Jr, Schork NJ, Kelsoe JR (2006) Suggestive evidence for association of the circadian genes PERIOD3 and ARNTL with bipolar disorder. Am J Med Genet B Neuropsychiatr Genet 141B(3):234-241. doi:10.1002/ajmg.b. 30252

8. Saus E, Soria V, Escaramis G, Vivarelli F, Crespo JM, Kagerbauer B, Menchon JM, Urretavizcaya M, Gratacos M, Estivill X (2010) Genetic variants and abnormal processing of pre-miR182 , a circadian clock modulator, in major depression patients with late insomnia. Hum Mol Genet 19(20):4017-4025. doi:10. 1093/hmg/ddq316

9. Wulff K, Gatti S, Wettstein JG, Foster RG (2010) Sleep and circadian rhythm disruption in psychiatric and neurodegenerative disease. Nat Rev 11(8):589-599. doi:10.1038/nrn2868

10. Paus T, Keshavan M, Giedd JN (2008) Why do many psychiatric disorders emerge during adolescence? Nat Rev 9(12):947-957

11. Giedd JN, Blumenthal J, Jeffries NO, Castellanos FX, Liu H, Zijdenbos A, Paus T, Evans AC, Rapoport JL (1999) Brain development during childhood and adolescence: a longitudinal MRI study. Nat Neurosci 2(10):861-863

12. Coghill D (2010) Adolescents in need: recognizing the broad impact of mental health problems in adolescents. Eur Child Adolesc Psychiatry 19(11):799-801. doi:10.1007/s00787-0100136-2

13. Buitelaar JK (2012) Adolescence as a turning point: for better and worse. Eur Child Adolesc Psychiatry 21(7):357-359. doi:10. 1007/s00787-012-0296-3

14. Tarokh L, Van Reen E, LeBourgeois M, Seifer R, Carskadon MA (2011) Sleep EEG provides evidence that cortical changes persist into late adolescence. Sleep 34(10):1385-1393

15. Tarokh L, Carskadon MA (2010) Developmental changes in the human sleep EEG during early adolescence. Sleep 33(6):801-809 
16. Feinberg I (1982) Schizophrenia: caused by a fault in programmed synaptic elimination during adolescence? J Psychiatr Res 17(4):319-334

17. Lustenberger C, Huber R (2012) High density electroencephalography in sleep research: potential, problems, future perspective. Front Neurol 3:77

18. Foundation NS (2006) Sleep in America poll summary findings

19. Hagenauer MH, Perryman JI, Lee TM, Carskadon MA (2009) Adolescent changes in the homeostatic and circadian regulation of sleep. Dev Neurosci 31(4):276-284

20. Carskadon MA (1982) The second decade. In: Guilleminault C (ed) Sleep and waking disorders: indications and techniques. Addison Wesley, Menlo Park, pp 99-125

21. Tarokh L, Raffray T, Van Reen E, Carskadon MA (2010) Physiology of normal sleep in adolescents. Adolesc Med State Art Rev 21(3):401-417 (vii)

22. Goldstein AN, Walker MP (2014) The role of sleep in emotional brain function. Annu Rev Clin Psychol 10:679-708. doi:10.1146/ annurev-clinpsy-032813-153716

23. Goldstein AN, Greer SM, Saletin JM, Harvey AG, Nitschke JB, Walker MP (2013) Tired and apprehensive: anxiety amplifies the impact of sleep loss on aversive brain anticipation. J Neurosci 33(26):10607-10615. doi:10.1523/JNEUROSCI.5578-12.2013

24. Van Dongen HP, Maislin G, Mullington JM, Dinges DF (2003) The cumulative cost of additional wakefulness: dose-response effects on neurobehavioral functions and sleep physiology from chronic sleep restriction and total sleep deprivation. Sleep 26(2):117-126

25. Glozier N, Martiniuk A, Patton G, Ivers R, Li Q, Hickie I, Senserrick T, Woodward M, Norton R, Stevenson M (2010) Short sleep duration in prevalent and persistent psychological distress in young adults: the DRIVE study. Sleep 33(9):1139-1145

26. Smedje H, Broman JE, Hetta J (2001) Associations between disturbed sleep and behavioural difficulties in 635 children aged six to eight years: a study based on parents' perceptions. Eur Child Adolesc Psychiatry 10(1):1-9

27. Magee L, Hale L (2012) Longitudinal associations between sleep duration and subsequent weight gain: a systematic review. Sleep Med Rev 16(3):231-241. doi:10.1016/j.smrv.2011.05.005

28. Kelly-Pieper K, Lamm C, Fennoy I (2011) Sleep and obesity in children: a clinical perspective. Minerva Pediatr 63(6):473-481

29. Bernert RA, Joiner TE Jr, Cukrowicz KC, Schmidt NB, Krakow B (2005) Suicidality and sleep disturbances. Sleep 28(9):1135-1141

30. McCall WV, Batson N, Webster M, Case LD, Joshi I, Derreberry T, McDonough A, Farris SR (2013) Nightmares and dysfunctional beliefs about sleep mediate the effect of insomnia symptoms on suicidal ideation. J Clin Sleep Med 9(2):135-140. doi:10. 5664/jcsm.2408
31. Agargun MY, Kara H, Solmaz M (1997) Sleep disturbances and suicidal behavior in patients with major depression. J Clin Psychiatry 58(6):249-251

32. Agargun MY, Besiroglu L, Cilli AS, Gulec M, Aydin A, Inci R, Selvi Y (2007) Nightmares, suicide attempts, and melancholic features in patients with unipolar major depression. J Affect Disord 98(3):267-270. doi:10.1016/j.jad.2006.08.005

33. Choquet M, Kovess V, Poutignat N (1993) Suicidal thoughts among adolescents: an intercultural approach. Adolescence 28(111):649-659

34. Wong MM, Brower KJ, Zucker RA (2011) Sleep problems, suicidal ideation, and self-harm behaviors in adolescence. J Psychiatr Res 45(4):505-511. doi:10.1016/j.jpsychires.2010.09.005

35. Foundation NS (2011) Sleep in America poll: technology use and sleep. National Sleep Foundation, Washington

36. Smith MT, Perlis ML, Park A, Smith MS, Pennington J, Giles DE, Buysse DJ (2002) Comparative meta-analysis of pharmacotherapy and behavior therapy for persistent insomnia. Am J Psychiatry 159(1):5-11

37. Morin CM, Bootzin RR, Buysse DJ, Edinger JD, Espie CA, Lichstein KL (2006) Psychological and behavioral treatment of insomnia: update of the recent evidence (1998-2004). Sleep 29(11):1398-1414

38. Chesson AL, Anderson WM Jr, Littner M, Davila D, Hartse K, Johnson S, Wise M, Rafecas J (1999) Practice parameters for the nonpharmacologic treatment of chronic insomnia. an American academy of sleep medicine report. standards of practice committee of the American academy of sleep medicine. Sleep 22(8):1128-1133

39. Jaycox LH, Asarnow JR, Sherbourne CD, Rea MM, LaBorde AP, Wells KB (2006) Adolescent primary care patients' preferences for depression treatment. Adm Policy Ment Health 33(2):198-207. doi:10.1007/s10488-006-0033-7

40. Sivertsen B, Omvik S, Pallesen S, Bjorvatn B, Havik OE, Kvale G, Nielsen GH, Nordhus IH (2006) Cognitive behavioral therapy vs zopiclone for treatment of chronic primary insomnia in older adults: a randomized controlled trial. JAMA 295(24):2851-2858. doi:10.1001/jama.295.24.2851

41. Wirz-Justice A, Benedetti F, Terman M (2009) Chronotherapeutics for affective disorders. Karger, Basel

42. Sateia MJ Nowell PD (2004) Insomnia. Lancet 364(9449):1959-1973. doi:10.1016/S0140-6736(04)17480-1

43. Wolfson AR, Carskadon MA (2003) Understanding adolescents' sleep patterns and school performance: a critical appraisal. Sleep Med Rev 7(6):491-506 